\title{
Undernutrition among Honduran children 12-71 months old
}

\author{
Penelope Nestel, ${ }^{1}$ Alejandro Melara, ${ }^{2}$ Jorge Rosado, ${ }^{3}$ \\ and Jose O. Mora ${ }^{4}$
}

ABSTRACT In 1996, the Ministry of Health of Honduras conducted a national micronutrient survey that included anthropometric measurements to determine the nutrition status of children 12-71 months old. Among the 1744 children who participated, 38\% of them were stunted, including $14 \%$ who were severely stunted; $24 \%$ were underweight, of which $4 \%$ were severely underweight; and $1 \%$ were wasted, of which $0.1 \%$ were severely wasted. The country can be divided into three groupings based on the level of stunting and underweight: 1) lowest prevalence: Tegucigalpa, San Pedro Sula, and medium cities; 2) medium prevalence: other urban areas, the rural north, and the rural south; and 3) highest prevalence: the rural west. Using logistic regression analysis, the important determinants of stunting were found to be: mother/caretaker's and father's schooling, source of water, the dominion (geographic location and strata) in which the child lived, and the "possession score" for ownership of such items as a radio, television, refrigerator, stereo system, and electric iron. The predictors for underweight were micronutrient status, diarrhea, maternal/caretaker's schooling, type of toilet, and possession score. Historical data indicate that the national prevalence of chronic undernutrition has changed little over the last 10 years despite the number of national food and nutrition plans implemented and the significant improvements in health services. It is possible that these positive interventions have been offset by the slow progress in economic development. Future nutrition interventions should take into account household-level perceived needs and priorities in order to set realistic nutrition targets.

Since the 1970s, the levels of undernutrition in many countries of Latin America and the Caribbean have declined. In those two areas, available per capita daily energy intake increased from about $2300 \mathrm{kcal}$ in 1960

\footnotetext{
1 International Life Sciences Institute, Washington, D.C., United States of America.

2 Ministry of Health, Tegucigalpa, Honduras.

3 National Institute of Nutrition, Mexico City, Mexico.

4 International Science and Technology Institute Inc., Arlington, Virginia, United States of America. Address correspondence to: Dr. Jose O. Mora, ISTI, 1820 North Fort Myer Drive, Suite 600, Arlington, VA 22209, United States of America.
}

to $2700 \mathrm{kcal}$ in 1990. Underweight declined from $17 \%$ in 1975 to $12 \%$ in 1989 , after which is has remained constant (1). Much of the improvement in nutrition status took place in the 1970s, but the improvement was not uniform across the countries. The limited improvement in nutrition status during the 1980s could have been due to the economic crisis that affected Latin America and the Caribbean.

Using national-level data, Mora and Dary (1) compared the prevalence of undernutrition in 20 countries in Latin America and the Caribbean. Their findings showed that Honduras had the second-highest prevalence of chronic undernutrition or stunting, after Haiti, and the fourth-highest prevalence of underweight, after Guatemala, Haiti, and Guyana.

In Honduras undernutrition in children has long been documented to be a problem of public health importance. The first national nutrition survey, carried out in 1966, found children were both lighter and shorter than the reference standards then widely used, the so-called Iowa reference curves (2). The high prevalence of physical growth retardation was still prevalent at the time of the second national nutrition survey, 
in 1987. The survey showed that of children 12-59 months old, $44 \%$ were stunted, $24 \%$ were underweight, and $2 \%$ were wasted (3). In the 1991 national survey, similar values were found for that same age group: $43 \%$ were stunted, $21 \%$ were underweight, and $2 \%$ were wasted (4).

Using data from the 1996 national micronutrient survey, this paper examines the association between nutrition status of preschool children and several nonbiological factors (geographic, social, and economic ones) and several biological factors (health and age-specific ones). The paper also identifies some risk factors that predispose children to being undernourished and that could be considered for improved targeting of nutrition and health care interventions.

\section{METHODS}

In this survey we used the 1988 Master Sampling Frame (MSF) developed by the General Office of Statistics and Censuses, which was updated in Tegucigalpa and the city of San Pedro Sula in 1991-1992 to include the new periurban areas. The MSF was divided into six strata or "dominions." Three of them were urban: 1) the capital city of Tegucigalpa, 2) the city of San Pedro Sula (SPS) and medium-sized cities (ones with a population between 20000 and 50 000, e.g., La Ceiba, Comayagua, Choloma, Puerto Cortés, La Lima, Danlí, Choluteca, and El Progreso), and 3) other urban areas-cities with a population of between 2000 and 20000 people and in which there was piped water; access by road, rail, or regular boat; a primary school; mail or telephone service; and electricity, a sewage system, or a health center. The other three dominions were rural areas, with villages and towns containing fewer than 2000 people. The three rural dominions-north, south, and westmatched the political boundaries of departments but excluded all urban communities in their respective areas. The rural south included the departments of Choluteca and Valle; the rural west, the departments of Ocotepeque,
La Paz, Lempira, and Intibucá; and the rural north, the departments of Yoro, Olancho, Santa Bárbara, Copán, Atlántida, El Paraíso, Francisco Morazán, Colón, and Cortés. The survey covered the whole country except the departments of Islas de la Bahía and Gracias a Dios, which are isolated and have a very low population density.

Among the nutrition indices of interest, vitamin A deficiency (VAD) was likely to be the rarest event; thus, this was the criterion used to determine the sample size. The prevalence of low plasma retinol was expected to be between $18 \%$ and $20 \%$, for which 308 children per dominion would be required to provide prevalence data with a $95 \%$ confidence interval and a sampling error of $5 \%$. This number would take into account a $20 \%$ attrition rate for whatever reason. A twostage sampling procedure was used, in which clusters were first selected and then houses within those clusters were chosen. For logistical reasons, 22 clusters were selected in each domain, using systematic selection from a random start with probability proportional to the number of households, based on the 1988 census data. Within each cluster, 22 households were randomly selected in Tegucigalpa, 19 in San Pedro Sula and medium-sized cities, 16 in other urban areas, 17 in the rural south, 14 in the rural west, and 18 in the rural north.

A household was defined as a person living alone or a group of people living together and sharing a common pot of food. An eligible household was one in which there was at least one child between the age of 12 and 71 months. Respondents were women who took care of the child daily, and included both mothers and caretakers. Data were collected by three field teams. Each team consisted of five members: a supervisor, two phlebotomists, and two interviewers. Within each team, an interviewer and phlebotomist worked as a pair. All the field staff had 2 weeks of training, which included standardization of anthropometric measurements. The questionnaire was pretested twice in an urban area and twice in a rural area before finalization. Field work was conducted between July and October 1996.

Data collected included standard household social and economic variables; morbidity (cough, runny nose, or diarrhea with $\geq 3$ or more watery stools/day) in the preceding 15 days ( 2 weeks), including the day of the survey; and pharmaceutical supplement use among children 12-71 months old. Child age was obtained from birth certificates or baptism records. Children were weighed to the nearest $100 \mathrm{~g}$, using a Salter hanging scale (United Nations Children's Fund, Copenhagen, Denmark), which was calibrated daily. Height was measured to the nearest $0.1 \mathrm{~cm}$, using a wooden anthropometer. Nutrition indicators were calculated using the U.S. Centers for Disease Control Anthropometric Software Package (Atlanta, Georgia, United States of America), which is based on the growth curves of the National Center for Health Statistics. Children with $z$ scores below -2 were considered undernourished, in line with standards of the World Health Organization (WHO) (5). The exclusion criteria for anthropometric values that are recommended by the WHO (6) were used, i.e., $4 z$-score units from the observed mean $z$ score for height/age, weight/age, and weight/height, with a maximum height/age $z$ score of +3 .

Two $\mathrm{mL}$ of venous blood were collected from the antecubital vein for plasma retinol and alpha-1-acid glycoprotein (AAGP) assays. For quality control, duplicate blood samples were taken from every tenth child. Blood was collected into a Sarstedt plasmagel tube using a butterfly needle and immediately placed in a cool box containing ice packs. Before collecting the blood, labeled tubes were covered in aluminum foil except for a small window that allowed the phlebotomist to see when the tube was full. At the end of each day, the blood samples were centrifuged and the plasma transferred to labeled vials covered in foil, after which they were stored in a freezer until being shipped to the Institute of Nutrition of Central America and Panama, in Guatemala City, Guatemala. For shipping, the plasma 
samples were packed in dry ice and sent by air.

Plasma retinol was determined spectrophotometrically following the method of Dary and Arroyave (7). Subclinical VAD was defined using the cut-off level of the WHO (8), of $<20 \mu \mathrm{g} / \mathrm{dL}$. The spectrophotometric method is not sufficiently specific for values below $20 \mu \mathrm{g} / \mathrm{dL}$ (Dary, personal communication), so separating the prevalence of severe deficiency from moderate and mild VAD was not possible. Children were defined at being at risk of VAD if their plasma retinol was between 20 and $30 \mu \mathrm{g} / \mathrm{dL}$. Children with a plasma retinol level of $30 \mu \mathrm{g} / \mathrm{dL}$ or higher were considered to have normal vitamin A status.

The concentration of AAGP, which peaks after 48 hours and remains high for about 120 hours before beginning to fall (9), was used as the marker of infection. It was determined using the Behring TurbiTime System (Behring, Marburg, Germany), an immunoturbidimetric assay in which human AAGP forms a precipitin with a specific antiserum. No guidelines currently exist for defining the presence of infection; based on data in the literature (10), a "high" AAGP level was defined as greater than $1.0 \mathrm{~g} / \mathrm{L}$.

Hemoglobin $(\mathrm{Hb})$ measurements were made on a drop of venous blood using a portable photometer (HemoCue, Ängelholm, Sweden). Anemia was defined as having an $\mathrm{Hb}$ level below $11 \mathrm{~g} / \mathrm{dL}$ at sea level (11). $\mathrm{Hb}$ levels were adjusted for altitude using the formula proposed by Yip ${ }^{5}$ adjusted $\mathrm{Hb}=\mathrm{Hb}-(-0.0323$ altitude + 0.0223 altitude $^{2}$ ), where altitude $=$ elevation in 1000 -foot units or in units of $1000 \mathrm{~m} 3$ 3.3.

Data were entered in Epi Info version 6 (U.S. Centers for Disease Control and Prevention, Atlanta, Georgia, United States) and exported to SPSS PC files. Analysis was done using SPSS for Windows version 5 (SPSS Inc, Chi-

\footnotetext{
5 Yip R. Altitude and hemoglobin elevations: implication for anemia screening and health risk of polycythemia. Paper presented at Eighth International Hypoxia Symposium, Hamilton, Ontario, 1993.
}

cago, Illinois, United States). A probability level of less than 0.05 was used to define statistical significance. In the bivariate analyses, the sample was weighted by the normalized sample weights, which was the product of the inverse of the sample weight, the household response rate, and the individual interview response rate. Sample sizes are presented as weighted observations. Logistic regression models were developed to predict stunting and underweight. In each model, the category in the bivariate analysis most positively associated with not being undernourished was generally used as the reference category. For ease of understanding, the ratios of the odds in the logistic regressions have been transformed into the ratios of probabilities or relative risks.

A technical committee set up by the Ministry of Health of Honduras reviewed all documents and survey procedures. Written informed consent was obtained from all mothers/caretakers. Ethical approval for the survey was obtained from the Human Subjects Committee of Johns Hopkins University.

\section{RESULTS}

A total of 2413 households were visited. The response rate was $96.7 \%$, and $52.2 \%$ of households were eligible, that is, had children 12-71 months old. Of the eligible households, $94.5 \%$ were successfully interviewed. Eighty-six percent of the children's data were obtained from their mothers, $11 \%$ from caretakers who had their own children, and $4 \%$ from caretakers who did not have any children. Anthropometric, $\mathrm{Hb}$, plasma retinol, and AAGP data were available for $98.3 \%, 93.8 \%, 88.7 \%$, and $91.3 \%$ of children, respectively.

\section{Demographic and socioeconomic status}

Overall, the mean and standard deviation of household size was 6.5 52.6 people. Households were larger $(P<0.02)$ in the rural south (mean $=7.0)$ and rural west (mean $=7.0)$ than else- where (mean, 6.1-6.6). The mean and standard deviation number of eligible women per household was 1.160 .3 , and there was no difference between dominions. The mean and standard deviation number of eligible children per household was 1.560 .8 and, again, there was no difference between the dominions. The mean and standard deviation age of mothers/caretakers with children 12-71 months old was 31.16 10.9 years, and the mean and standard deviation age of the partner of mothers/caretakers was 36.1 610.7 years. Neither mother/caretaker's age nor her partner's age varied by dominion.

There was no difference between dominions in the gender of the children $(51.3 \%$ boys, $48.7 \%$ girls) or in their mean age (40.2 617.2 months), indicating that the sample was not biased by these parameters.

Thirty percent of mothers/caretakers were married, $46 \%$ were in a free union, and $24 \%$ were neither in a free union nor married (Table 1). Compared with the other dominions, more mothers/caretakers in the rural west were married, and more mothers/ caretakers in the urban areas were not in a free union or married.

Overall, $18 \%$ of mothers/caretakers had never been to school, $65 \%$ had attended at least some primary school, and the remaining $17 \%$ had attended secondary school (Table 1). The lowest level of school attendance was in the rural west, where $32 \%$ of mothers/ caretakers had not been to school. Even in the urban areas, only about one out of three mothers/caretakers had attended at least grade 1 of secondary school. The overall pattern for the schooling of the partners of mothers/caretakers was similar to that for the mothers/caretakers. However, in the rural south more partners than mothers/caretakers had not been to school than in the other dominions.

Besides their household responsibilities, $43 \%$ of mothers/caretakers worked for an income, a pattern that was more evident in the urban areas than in the rural ones (Table 1). Ninety-eight percent of the partners of mothers/caretakers worked, with no difference between dominions. Most 
TABLE 1. Percent distribution of demographic and social and economic factors by dominion, national micronutrient survey, Honduras, 1996

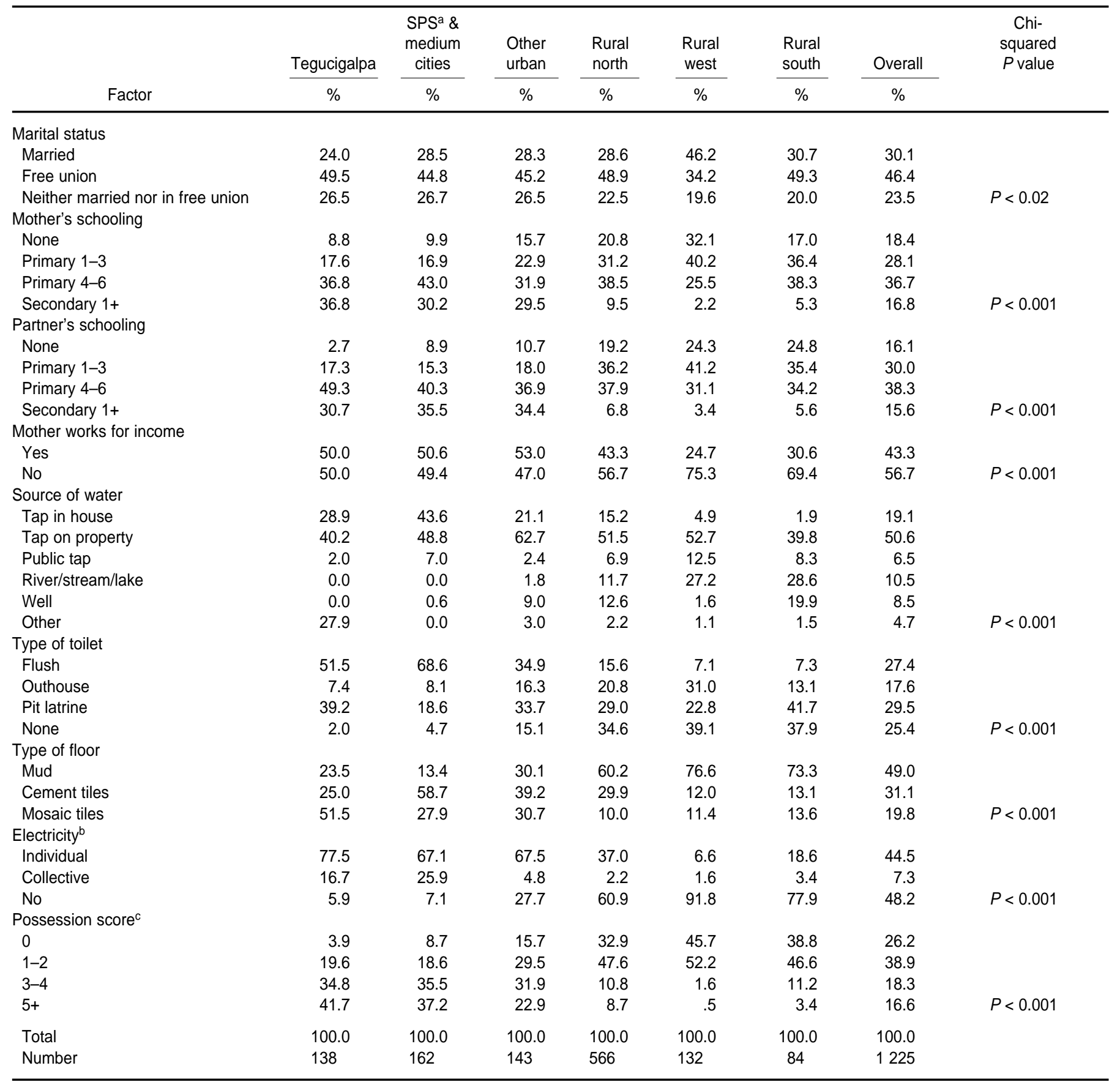

a SPS = San Pedro Sula.

b "Individual" electrical power supplies a single household; "collective" electrical power serves several households sharing and paying for a single electrical line.

${ }^{c}$ A score of 1 point each was applied to ownership of a radio, TV, refrigerator, stereo system, electric iron, blender, and telephone.

of the partners worked in agriculture $(48 \%)$ or as independent skilled laborers $(24 \%)$.

Overall, $76 \%$ of households obtained water from some kind of a tap (Table 1). That included 19\% with tap water in the house, $51 \%$ with a tap on their property, and the remainder with a tap in the street. More households in SPS and medium cities had tap water in the house than elsewhere. In contrast, more than $25 \%$ of households in both the rural west and the rural south were dependent on open-air sources of water. In Tegucigalpa a large proportion of households used other sources of water, such as buying bottled purified water. 
Seventy-five percent of households had an adequate sanitary system to dispose of excreta, of which $27 \%$ had a flush toilet and $47 \%$ had a pit latrine or outhouse (Table 1). Outhouses were more common in the rural west, the rural south, and rural north. As expected, more households in the larger metropolitan areas had a flush toilet; this was especially true in SPS and medium cities.

Close to one-half of all households had a mud floor (Table 1); that was much more common in the rural areas. Most households in Tegucigalpa had mosaic tiled floors, while those in SPS and medium cities tended to have cement tile floors. Overall, $48 \%$ of households did not have electricity. This was more often the case in the rural areas, where $92 \%$ of households in the rural west, $78 \%$ in the rural south, and $61 \%$ in the rural north did not have electricity (Table 1).

Households were asked whether they owned a variety of possessions. Of the households, $67 \%$ owned a radio, $41 \%$ a television, $23 \%$ a refrigerator, $15 \%$ a stereo system, $36 \%$ an electric iron, $19 \%$ a blender, and 5\% a telephone. A score of one was applied to each item owned and the sum was called the "possession score." Because all these items except a radio typically operate from a local community electrical system, the ability of this possession variable to capture differences in household economic status was limited. Nevertheless, Table 1 shows that $26 \%$ of households did not own any of those items, 39\% owned one or two, $18 \%$ owned three or four, and $17 \%$ owned five or more of them. Over one-half of households in the urban areas owned three or more of the items. Households in the rural west were the least likely to own the items listed. Given that few households in the rural areas had electricity, this finding was expected.

\section{Child morbidity}

Overall, among children 12-71 months old, $30 \%$ reportedly had had diarrhea in the 2 weeks preceding the survey (Table 2). Among children 12-59 months old, 32\% reportedly had had diarrhea in that period. Table 2 also shows $56 \%$ of children 12-71 months old reportedly had had a cough and $66 \%$ a runny nose in the preceding 2 weeks. In addition, $24 \%$ of children had a recent history of infection, based on an elevated AAGP level. Having a runny nose and cough but not diarrhea varied by dominion, with the prevalence being higher in the rural dominions than in the urban ones.

There were no gender differences in the prevalence of any of the three morbidities. There were, however, significant age-related patterns for all three morbidities (Table 2). For example, among children 12-23 months old, the prevalence of diarrhea was over $50 \%$. However, this prevalence steadily declined until the age range of 48-59 months, after which it leveled off at under $20 \%$. Similar but smaller declines in the prevalence of cough and runny nose were also found for older children (Table 2).

\section{Nutrition status of children}

Of Honduran children 12-71 months old, $38.5 \%$ were stunted, $24.5 \%$ were

TABLE 2. Percentage of children 12-71 months of age with diarrhea, cough, and runny nose in the preceding 2 weeks by dominion and age group, national micronutrient survey, Honduras, 1996

\begin{tabular}{|c|c|c|c|c|}
\hline Category & $\begin{array}{c}\text { Diarrhea } \\
\%\end{array}$ & $\begin{array}{c}\text { Cough } \\
\%\end{array}$ & $\frac{\text { Runny nose }}{\%}$ & $\begin{array}{c}\text { No. of } \\
\text { children }\end{array}$ \\
\hline \multicolumn{5}{|l|}{ Dominion } \\
\hline Tegucigalpa & 23.3 & 50.5 & 63.6 & 191 \\
\hline SPS ${ }^{a}$ \& medium cities & 27.9 & 50.4 & 58.3 & 226 \\
\hline Other urban & 30.9 & 50.8 & 59.4 & 212 \\
\hline Rural north & 32.5 & 60.3 & 70.0 & 771 \\
\hline Rural west & 30.1 & 55.6 & 71.7 & 205 \\
\hline Rural south & 25.2 & 56.9 & 67.6 & 133 \\
\hline Chi-squared $P$ value & $n s^{b}$ & $P<0.05$ & $P<0.002$ & \\
\hline \multicolumn{5}{|l|}{ Age group } \\
\hline 12-23 months & 53.6 & 60.6 & 71.5 & 384 \\
\hline 24-35 months & 33.4 & 59.6 & 76.7 & 394 \\
\hline 36-47 months & 21.3 & 55.9 & 63.6 & 333 \\
\hline 48-59 months & 16.1 & 51.4 & 58.3 & 343 \\
\hline 60-71 months & 17.9 & 49.9 & 58.2 & 283 \\
\hline Chi-squared $P$ value & $P<0.001$ & $P<0.02$ & $P<0.001$ & \\
\hline Overall (12-59 mo) & 31.9 & 57.1 & 68.0 & 1454 \\
\hline Overall (12-71 mo) & 29.9 & 56.0 & 66.5 & 1744 \\
\hline
\end{tabular}

a SPS = San Pedro Sula

${ }^{\mathrm{b}} \mathrm{ns}=$ not significant. underweight, and $1.5 \%$ were wasted (Table 3). The prevalence of stunting and underweight were about 17 and 11 times, respectively, the levels expected in a well-nourished healthy population, according to the WHO growth standards. In contrast, the level of wasting was within the expected range.

The data also show that $13.6 \%$ of the children were severely stunted and $4.0 \%$ of the children were severely underweight. The prevalence of severe wasting was $0.1 \%$ (Table 3 ). These data indicate levels of severe underweight and severe stunting were very high, respectively 40 and 136 times the levels expected in a well-nourished healthy population. The prevalence of severe stunting peaked in the age range of 36-47 months. On the other hand, the prevalence of severe underweight was already high by the age of 12-23 months, and declined after the age range of 36-47 months (Table 3).

There were noticeable dominion differences in nutrition status (Table 4). Stunting was highest in the rural west, where more than $60 \%$ of children were stunted, a figure at least 20 percentage points higher than in the other domin- 
TABLE 3. Percentage of children 12-71 months of age severely and moderately stunted, underweight, and wasted by age group, national micronutrient survey, Honduras, 1996

\begin{tabular}{|c|c|c|c|c|c|c|c|c|c|c|}
\hline \multirow[b]{3}{*}{ Age group } & \multicolumn{3}{|c|}{ Stunted $^{\mathrm{a}}$} & \multicolumn{3}{|c|}{ Underweighta } & \multicolumn{3}{|c|}{ Wasted $^{\mathrm{a}}$} & \multirow{3}{*}{ Number } \\
\hline & Severe & Moderate & Total & Severe & Moderate & Total & Severe & Moderate & Total & \\
\hline & $\%$ & $\%$ & $\%$ & $\%$ & $\%$ & $\%$ & $\%$ & $\%$ & $\%$ & \\
\hline 24-35 months & 13.0 & 26.8 & 39.8 & 4.5 & 21.4 & 25.9 & 0.0 & 1.0 & 1.0 & 389 \\
\hline 36-47 months & 18.5 & 21.5 & 40.0 & 5.3 & 18.1 & 23.4 & 0.1 & 0.1 & 0.2 & 331 \\
\hline 48-59 months & 12.8 & 25.0 & 37.8 & 3.0 & 17.2 & 20.2 & 0.0 & 0.3 & 0.3 & 342 \\
\hline Chi-squared $P$ value & & & $P<0.02$ & & & $P<0.02$ & & & $N A^{b}$ & \\
\hline Overall & 13.6 & 24.9 & 38.5 & 4.0 & 20.5 & 24.5 & 0.1 & 1.4 & 1.5 & 1725 \\
\hline
\end{tabular}

a Severe and moderate = below -3 and -2 standard deviations, respectively, of the reference growth curves of the U.S. National Center for Health Statistics.

b $N A=$ not applicable; cell numbers too small for a valid chi-squared test.

ions. Thirty-eight percent of children in the rural west were underweight, again a proportion higher than in any of the other dominions. Indeed, Honduras can be divided into three groups based on the prevalence of stunting and underweight: 1) lowest prevalence, in Tegucigalpa and SPS and medium cities; 2) medium prevalence, in other urban areas, the rural north, and the rural south; and 3) the highest prevalence, in the rural west. This pattern was also found for severe stunting and severe underweight (data not shown).

Among the socioeconomic variables studied, the age of the mother/caretaker's partner was not associated with nutrition status. Similarly, whether the mother/caretaker or her partner worked for an income was not associated with nutrition status. In contrast, children were less likely to be chronically undernourished if their mother/ caretaker was married or if she or her partner had attended secondary school (Table 4). Fewer children whose mothers/caretakers were over 40 years old were underweight.

Having tap water in the house and having a flush toilet were associated with lower levels of chronic undernutrition. Other indicators that reflect higher social and economic status were associated with better nutrition status. These included having a tiled floor, electricity in the house, or a greater number of possessions (Table 4). Many of these social and economic factors, however, not only interact with each other but also with dominion. This interaction needs to be taken into account when assessing risk factors for undernutrition.

As for biological factors, there were no age- or gender-specific patterns in the prevalence of undernutrition for children 12-71 months old. Children who had had diarrhea in the preceding 2 weeks were more likely to be chronically or acutely undernourished than those who had not (Table 4). Cough and a runny nose were also associated with a higher level of underweight but not stunting or wasting. A recent history of these illnesses may reflect the short-term cumulative association that repeated bouts of these infections have with retarded growth, and vice versa.

Overall, among children 12-71 months old, having received iron supplements in the preceding 6 months was protective against chronic undernutrition. A similar finding was observed for underweight among children who had ever received vitamin $\mathrm{A}$ and among those who had been dewormed using antihelminth therapy in the preceding 6 months. These findings could reflect the direct association between supplementation and nutrition status or the indirect association with better use of health care facilities. Underweight was also associated with being anemic $(\mathrm{Hb}$ below $11 \mathrm{~g} / \mathrm{dL})$, as well as with being both anemic and vitamin A deficient (plasma retinol below $20 \mu \mathrm{g} / \mathrm{dL}$ ).

\section{Risk factors for stunting and underweight}

The socioeconomic and health variables identified as important in the bivariate analyses were used in a logistic regression model to determine their net effects on stunting and underweight. In Table 4, the ratios or relative risks (RRs) included are only those that were significant in the logistic regression model; where there are no values in the table, the variables were no longer significant after controlling for the other variables in the model.

For stunting among Honduran children 12-71 months old the important determinants were mother/caretaker's and father's schooling, source of water, possession score, and dominion (Table 4). For mother/caretaker's schooling, having attended at least grade 1 of secondary school was the reference category, with a numerical value of 1.00.

In comparison to children whose mother/caretaker had attended at least grade 1 of secondary school, there was an $83 \%$ higher relative risk of stunting among children whose mother/caretaker had never been to school, a statistically significant difference. Among children whose mother/caretaker had only attended grade 1,2 , or 3 of primary school, the relative risk was $58 \%$ higher, again a statistically significant difference. Children whose mother/ caretaker had attended primary grade 4,5 , or 6 were $21 \%$ more likely to be 
stunted, but this difference was not statistically significant.

Children from households in which the mother's partner had attended at least grade 1 of secondary school were $32 \%$ less likely to be stunted than children whose mother's partner did not live with them (reference category).

Children from households that got water from a public tap were $72 \%$ more likely to be stunted than those from households that had water piped to the home, even after controlling for other social and economic factors. The household possession score, which was a proxy for wealth, also predicted stunting. In comparison to children from households with five or more possessions, children from households that had no possessions were 3.25 times as likely to be stunted. For children from households with one or two possessions, the net relative risk was 2.43 .

Dominion was significantly associated with the net relative risk of stunting; children in the rural west were at $39 \%$ greater risk of being stunted than those in Tegucigalpa.

None of the biological variables studied was a good predictor of stunting.

For underweight among children 12-71 months old, the predictive nonbiological and biological factors were micronutrient status, diarrhea, maternal/caretaker's schooling, type of toilet, and possession score (Table 4). Children with a normal plasma retinol (> $20 \mu \mathrm{g} / \mathrm{L}$ ) but a low hemoglobin level ( $<11 \mathrm{~g} / \mathrm{dL})$ were $28 \%$ more likely to be underweight than children having both a normal plasma retinol level and a normal hemoglobin level. Children with concurrent low hemoglobin and plasma retinol levels were 95\% more likely to be underweight than children with neither deficiency. Diarrhea, which has an immediate effect on energy balance, increased the risk of being underweight by $32 \%$.

In comparison to children from households with a possession score of 5 or more, children from households with a possession score of 0 had a net relative risk of underweight of 2.38. For children from households with a possession score of 1 or 2 , the relative risk was 1.80 . Having a flush
TABLE 4. Percentage of children 12-71 months of age stunted, underweight, and wasted by background factors, national micronutrient survey, Honduras, 1996

\begin{tabular}{|c|c|c|c|c|c|}
\hline Factor & $\begin{array}{c}\text { Stunted } \\
\%\end{array}$ & $\begin{array}{l}\text { Net relative } \\
\text { risk of } \\
\text { stunting }\end{array}$ & $\begin{array}{c}\text { Underweight } \\
\%\end{array}$ & $\begin{array}{l}\text { Net relative } \\
\text { risk of } \\
\text { underweight }\end{array}$ & $\begin{array}{c}\text { Wasted } \\
\%\end{array}$ \\
\hline \multicolumn{6}{|l|}{ Dominion } \\
\hline Tegucigalpa & 24.9 & $1.00^{\mathrm{b}}$ & 10.0 & & 0.7 \\
\hline $\mathrm{SPS}^{\mathrm{C}} \&$ medium cities & 17.9 & 0.72 & 9.4 & & 1.3 \\
\hline Other urban & 35.5 & 1.21 & 22.1 & & 1.2 \\
\hline Rural north & 42.5 & 0.99 & 29.4 & & 1.6 \\
\hline Rural west & 62.7 & 1.39 & 37.6 & & 1.5 \\
\hline Rural south & $\begin{array}{c}36.5 \\
P<0.001^{d}\end{array}$ & 0.74 & $\begin{array}{c}26.0 \\
P<0.001\end{array}$ & & $\begin{array}{l}2.2 \\
n s^{e}\end{array}$ \\
\hline \multicolumn{6}{|l|}{ Marital status } \\
\hline Married & 32.1 & & 19.7 & & 1.0 \\
\hline Free union & 42.7 & & 28.7 & & 2.2 \\
\hline $\begin{array}{l}\text { Neither married nor } \\
\text { in free union }\end{array}$ & $\begin{array}{c}38.3 \\
P<0.001\end{array}$ & & $\begin{array}{c}22.2 \\
P<0.001\end{array}$ & & $\begin{array}{c}0.3 \\
P<0.05\end{array}$ \\
\hline \multicolumn{6}{|l|}{ Mother's schooling } \\
\hline None & 56.7 & $1.83^{f}$ & 39.9 & $1.99^{f}$ & 3.7 \\
\hline Primary 1-3 & 46.5 & $1.58^{f}$ & 28.8 & 1.54 & 0.5 \\
\hline Primary 4-6 & 32.0 & 1.21 & 19.5 & 1.04 & 1.2 \\
\hline Secondary 1+ & $\begin{array}{c}17.7 \\
P<0.001\end{array}$ & $1.00^{\mathrm{b}}$ & $\begin{array}{c}10.5 \\
P<0.001\end{array}$ & $1.00^{\mathrm{b}}$ & $\begin{array}{l}1.2 \\
\mathrm{NA}^{9}\end{array}$ \\
\hline \multicolumn{6}{|l|}{ Partner's schooling } \\
\hline Not applicable & 38.6 & $1.00^{\mathrm{b}}$ & 22.5 & & 0.9 \\
\hline None & 52.6 & 1.01 & 39.9 & & 3.6 \\
\hline Primary 1-3 & 49.8 & 1.16 & 31.5 & & 1.0 \\
\hline Primary 4-6 & 32.8 & 0.95 & 20.9 & & 1.4 \\
\hline Secondary 1+ & $\begin{array}{c}13.8 \\
P<0.001\end{array}$ & $0.68^{f}$ & $\begin{array}{c}6.0 \\
P<0.001\end{array}$ & & $\begin{array}{l}1.0 \\
\text { NA }\end{array}$ \\
\hline \multicolumn{6}{|l|}{ Mother's age (years) } \\
\hline$<20$ & 36.6 & & 23.2 & & 1.1 \\
\hline $20-24$ & 40.5 & & 25.8 & & 2.0 \\
\hline $25-29$ & 39.4 & & 22.0 & & 1.4 \\
\hline $30-34$ & 40.4 & & 31.4 & & 1.3 \\
\hline $35-39$ & 32.9 & & 24.1 & & 1.1 \\
\hline $40+$ & 37.3 & & 20.0 & & 1.2 \\
\hline & ns & & $P<0.05$ & & NA \\
\hline \multicolumn{6}{|l|}{ Source of water } \\
\hline Tap in house & 20.3 & $1.00^{\mathrm{b}}$ & 11.1 & & 0.8 \\
\hline Tap on property & 38.2 & 0.93 & 24.6 & & 1.4 \\
\hline Public tap & 63.2 & $1.72^{\dagger}$ & 36.3 & & 4.0 \\
\hline River/stream/lake & 60.6 & 1.18 & 42.6 & & 2.4 \\
\hline Well & 32.2 & 0.77 & 22.4 & & 0.3 \\
\hline Other & $\begin{array}{c}37.5 \\
P<0.001\end{array}$ & 1.26 & $\begin{array}{c}21.1 \\
P<0.001\end{array}$ & & $\begin{array}{l}0.0 \\
\text { NA }\end{array}$ \\
\hline \multicolumn{6}{|l|}{ Type of toilet } \\
\hline None & 53.2 & & 36.6 & $2.33^{f}$ & 2.1 \\
\hline Outhouse & 38.2 & & 27.4 & $2.34^{\dagger}$ & 2.1 \\
\hline Pit latrine & 42.4 & & 26.0 & $2.22^{f}$ & 1.4 \\
\hline Flush & $\begin{array}{c}18.9 \\
P<0.001\end{array}$ & & $\begin{array}{c}8.3 \\
P<0.001\end{array}$ & $1.00^{\mathrm{b}}$ & $\begin{array}{l}0.4 \\
\text { NA }\end{array}$ \\
\hline \multicolumn{6}{|l|}{ Type of floor } \\
\hline Mud & 50.3 & & 32.1 & & 2.2 \\
\hline Cement tiles & 29.5 & & 19.5 & & 0.8 \\
\hline Mosaic tiles & 21.0 & & 12.2 & & 0.5 \\
\hline & $P<0.001$ & & $P<0.001$ & & NA \\
\hline \multicolumn{6}{|l|}{ Electricity ${ }^{h}$} \\
\hline Individual & 25.4 & & 14.1 & & 0.6 \\
\hline Collective & 35.7 & & 22.3 & & 0.9 \\
\hline \multirow{2}{*}{ No } & 50.7 & & 34.0 & & 1.9 \\
\hline & $P<0.001$ & & $P<0.001$ & & NA \\
\hline
\end{tabular}


TABLE 4. (Continued)

\begin{tabular}{|c|c|c|c|c|c|}
\hline Factor & $\begin{array}{c}\text { Stunted } \\
\%\end{array}$ & $\begin{array}{c}\text { Net relative } \\
\text { risk of } \\
\text { stunting }\end{array}$ & $\begin{array}{c}\text { Underweight } \\
\%\end{array}$ & $\begin{array}{l}\text { Net relative } \\
\text { risk of } \\
\text { underweight }\end{array}$ & $\begin{array}{c}\text { Wasted } \\
\%\end{array}$ \\
\hline \multicolumn{6}{|l|}{ Possession score } \\
\hline 0 & 59.5 & $3.25^{f}$ & 41.6 & $2.38^{f}$ & 2.5 \\
\hline $1-2$ & 41.8 & $2.43^{f}$ & 25.7 & $1.80^{f}$ & 1.5 \\
\hline $3-4$ & 20.5 & 1.36 & 9.1 & 0.79 & 0.0 \\
\hline $5+$ & $\begin{array}{c}13.5 \\
P<0.001\end{array}$ & $1.00^{\mathrm{b}}$ & $\begin{array}{c}9.1 \\
P<0.001\end{array}$ & $1.00^{\mathrm{b}}$ & $\begin{array}{l}0.9 \\
\text { NA }\end{array}$ \\
\hline \multicolumn{6}{|l|}{ Diarrhea last 2 weeks } \\
\hline Yes & 44.8 & & 33.2 & $1.32^{f}$ & 2.8 \\
\hline No & $\begin{array}{c}36.0 \\
P<0.001\end{array}$ & & $\begin{array}{c}20.9 \\
P<0.001\end{array}$ & 1.00 & $\begin{array}{c}0.9 \\
P<0.005\end{array}$ \\
\hline \multicolumn{6}{|l|}{ Cough last 2 weeks } \\
\hline Yes & 40.5 & & 26.4 & & 1.2 \\
\hline No & 36.2 & & 22.2 & & 1.8 \\
\hline & $\mathrm{ns}$ & & $P<0.05$ & & ns \\
\hline \multicolumn{6}{|c|}{ Runny nose last 2 weeks } \\
\hline Yes & 40.1 & & 26.2 & & 1.2 \\
\hline No & 35.6 & & 21.4 & & 1.8 \\
\hline & ns & & $P<0.05$ & & ns \\
\hline \multicolumn{6}{|l|}{ Received Fe last 6 mo } \\
\hline Yes & 32.6 & & 21.1 & & 1.5 \\
\hline No & 41.2 & & 26.1 & & 1.4 \\
\hline & $P<0.001$ & & $P<0.05$ & & ns \\
\hline \multicolumn{6}{|l|}{ Ever received vitamin $A$} \\
\hline Yes & 39.6 & & 24.0 & & 1.6 \\
\hline No & 42.5 & & 33.0 & & 1.8 \\
\hline & ns & & $P<0.05$ & & NA \\
\hline \multicolumn{6}{|l|}{ Antihelminth last 6 mo } \\
\hline Yes & 36.1 & & 21.0 & & 1.0 \\
\hline No & 40.3 & & 27.2 & & 1.8 \\
\hline & ns & & $P<0.005$ & & $\mathrm{~ns}$ \\
\hline \multicolumn{6}{|l|}{ Micronutrient status } \\
\hline VAD' and IDA & 53.6 & & 47.1 & $1.95^{\mathrm{e}}$ & 1.6 \\
\hline VAD only & 53.2 & & 33.3 & 0.96 & 1.8 \\
\hline IDA only & 39.3 & & 25.9 & $1.28^{\mathrm{b}}$ & 2.3 \\
\hline Neither VAD nor IDA & 34.2 & & 19.6 & $1.00^{\mathrm{b}}$ & 1.0 \\
\hline & $P<0.001$ & & $P<0.001$ & & NA \\
\hline Overall & 38.5 & & 24.5 & & 1.4 \\
\hline Number & 1725 & 1628 & 1725 & 1516 & 1725 \\
\hline
\end{tabular}

a The relative risks included are only those that were significant in the logistic regression model; where there are no values in the table, the variables were no longer significant after controlling for the other variables in the model.

b Overall $P<0.05$.

c SPS = San Pedro Sula.

d Throughout, level of significance based on chi-squared test.

${ }^{e}$ ns $=$ not significant.

f $P<0.05$ compared with reference category.

g NA = not applicable; cell numbers too small for a valid chi-squared test.

h "Individual" electrical power supplies a single household; "collective" electrical power serves several households sharing and paying for a single electrical line.

VAD = vitamin A deficiency.

i IDA = iron deficiency anemia.

toilet was protective against being underweight. Children from households that did not have a flush toilet were at more than double the risk of being underweight than those from households with a flush toilet. Finally, maternal education was protective against underweight. Children whose mother/caretaker had not attended school were at double the risk of being underweight compared with those whose mother/caretaker had attended at least grade 1 of secondary school.

\section{DISCUSSION}

The findings from this national survey reflect that, overall, the socioeconomic situation of households in rural areas was worse than that in urban ones and, among the rural areas, living conditions in the south and west were more difficult than in the north. These findings were consistent with existing data and reflect the lack of basic services, which is a consequence of the inequitable distribution of resources versus the needs of various segments of the population. Decisionmakers at both the national and local level need to realize that these health inequities will not necessarily be resolved until there is a more equal distribution of resources or services.

Symptoms of respiratory infection were present in over one-half of the children between 12 and 71 months of age. Diarrhea was less prevalent, but it still affected $30 \%$ of children. In contrast, the 1997 Family Health and Epidemiology Survey (12) found that the prevalence of diarrhea among children under 5 years of age had declined from $30.2 \%$ to $19.3 \%$ between 1987 and 1996. Data on diarrhea are affected by such factors as how the question is asked, and the season. This may account for the different results found in the two surveys. For example, while the 1996 micronutrient survey was carried out after the rains, between July and October, the Family Health and Epidemiology Survey was conducted between February and August, during and immediately after the rains.

Overall, data from the micronutrient survey showed that morbidities declined with age. For example, more children under 3 years old had had diarrhea, cough, or a runny nose in the preceding two weeks than was true for older children. The high prevalence of diarrhea among the younger children could have been related to food preparation and feeding practices and to increased exposure to pathogens as children become increasingly mobile throughout their first 2-3 years of life. Children may become more immune to infections as they get older because their living environment predisposes 
them to a gradual increase in the colonization of various bacteria and viruses in the intestinal gut, which compete with each other and determine the presence of infection. Targeting health education messages to mothers with children under 3 years of age may be an important option to consider.

Nearly two out of five children were stunted, a further one out of four was underweight, and a very few were wasted. These were all indications that undernutrition in children 12-71 months old was chronic. Undernutrition, however, was not associated with age, which indicated that by the age of 12 months the nutritional damage of poor infant feeding practices coupled with morbidity had already affected child growth negatively. It also suggested that during their preschool years, Honduran children did not have the opportunity for catch-up growth to compensate for the nutritional harm imposed in infancy.

Logistic regression analyses showed that chronic undernutrition was largely determined by parental schooling and factors generally associated with poverty. The results for maternal education show the beneficial effects of maternal schooling beyond primary grade 3 per se on the risk of stunting and underweight of children. The lower risk of stunting among children whose mother's partner's had been to secondary school may have been a reflection of a paternal interest in child nutrition, rather than higher income, given that other proxies for wealth were already in the model.

The finding that children from households obtaining water from public taps were at greater risk of being stunted suggests this water may be contaminated, predisposing children to repeated bouts of infection and trapping them in a vicious cycle of undernutrition-infection that compromises their growth. Having piped water in the home also reflect higher income levels and / or that the environmental sanitation in these homes was better. It is well known, for example, that where water is not readily available, food hygiene is frequently poor, which increases the risk of pathogen contamination and exposure to illnesses. Indeed, having a flush toilet in the home greatly reduced the risk of being underweight. Because wealth was already controlled for through possession score, this result probably reflected the importance of environmental hygiene on underweight.

Among the determinants for risk of being underweight were a recent history of diarrhea, which directly affects body weight, and micronutrient status (more so anemia than subclinical VAD). These data suggested that both the quantity of the diet and its quality were inadequate. In contrast, none of the biological variables studied were good predictors of stunting. This was expected, given that stunting is the cumulative effect of poor nutrition and that most of the biological indicators were based on recent events.

Although living in a particular dominion was a risk factor for stunting, it did not by itself cause stunting. Thus, the dominion must have been acting as a proxy for other factors that were not measured in the survey and that were associated with chronic poor nutrition, such as access to food, feeding practices, child care practices, and parasitic infestations. It should be noted, however, that the rural west includes the departments of Lempira, Intibucá, and La Paz, where the Lenca ethnic group, known for their short stature, reside.

Since 1987 in Honduras, four nationally representative surveys have collected height and weight data on children under 5 years of age. Trend analysis done by Grummer-Strawn ${ }^{6}$ has shown that, while there has been a slight reduction in the prevalence of stunting over the last 10 years, the national prevalence remains very high and there has been no change in the prevalence of underweight. Historically, wasting or acute undernutrition has not been a public health problem.

There have been small changes in the very high level of chronic undernutri-

\footnotetext{
Grummer-Strawn, L. Trends in the nutritional status of children in Honduras, 1987-1996 [unpublished report]. Atlanta, GA: Centers for Disease Control and Prevention; 1997.
}

tion in children over the past ten years. This is intriguing, given the number of programs implemented and other changes that have occurred. These include several national food and nutrition plans (although possibly not implemented very effectively); large amounts of resources spent on nutrition programs, particularly food distribution activities for women and children; and significant improvements in health services as reflected in increased immunization coverage (at least $80 \%$ coverage for each immunogen), increased diarrheal disease control, reduced infant mortality (29/1 000 live births in 1996), decreased under-5 mortality (35/1 000 live births in 1996), and improved breast-feeding practices (13).

On the other hand, the observed trends in nutrition are possibly expected when compared with the economic indicators (13). Honduras is one of the poorest countries in the Region of the Americas, with a per capita gross national product (GNP) of $\$$ US 600 in 1995. The annual per capita GNP growth rate was only $1.1 \%$ between 1965 and 1980 and decreased to $0.1 \%$ between 1985 and 1995. Between 1985 and 1995 the inflation rate was $14 \%$. An estimated $47 \%$ of the population was living on less than $\$ 1.00$ per day during the 1990-1996 period. Taken together, these data show that the social and economic constraints that families face are daunting and that the constraints' impact on nutrition status cannot be completely overcome by just improved access to health care.

The Ministry of Health of Honduras is implementing an Integrated Child Care Program, in which growth monitoring is the central component. The training component and the information/education/communication component of the program are based on knowledge provided by existing epidemiological and qualitative surveys, which include biochemical, dietary, and other nutrition-related data. About $70 \%$ of households have good access to health care, and there are significant efforts toward strengthening health care delivery at the primary level. However, for the program to be a success, it will be important for the Ministry of Health 
to understand what households perceive their priorities to be, how nutrition and health considerations fit into these priorities, and how the perceived priorities can be achieved within the context of the existing constraints that households face. The effectiveness of interventions needs to be monitored and measured in terms of community perceptions of priorities. Otherwise, community "ownership" of the program is unlikely, and it is doubtful that objecacciones para su prevención y control en América Latina y el Caribe, 1994. Bol Oficina Sanit Panam 1994;117(6):519-528.

2. Interdepartmental Committee for National Defense/Instituto de Nutrición de Centro América y Panamá. Nutritional evaluation of the population of Central America and Panama. Washington, DC: U.S. Department of Health, Education, and Welfare; 1972. (DHEW Publication No HSM72-8120).

3. Barahona F, Soto J, O'Connor G, Madariaga A. Encuesta nacional de epidemiología y salud familiar. Datos preliminares. Tegucigalpa: Ministerio de Salud Pública de Honduras; 1987.

4. Honduras, Ministry of Health. Epidemiology and Family Health Survey, 1991/92. Tegucigalpa: MOH; 1994.

5. World Health Organization. Measuring change in nutritional status. Geneva: WHO; 1989. tives will be achieved, even though services are, in principle, available.

Acknowledgments. The survey was implemented by the Ministry of Health in collaboration with the International Eye Foundation. Technical and financial assistance was provided through the Opportunities for Micronutrient Interventions (OMNI) Proj- ect of the U.S. Agency for International Development, under contract HRN-C00-93-00025-08. Dr. Omar Dary's laboratory at the Institute of Nutrition of Central America and Panama conducted the retinol and AAGP assays. Thanks are due to the field teams and households who made the survey possible and to Dr. Frances Davidson of the U.S. Agency for International Development, Washington, D.C., for support and helpful comments.

\section{REFERENCES}

6. World Health Organization. Physical status: the use and interpretation of anthropometry, report of a WHO expert committee. Geneva: WHO; 1995. (WHO Technical Report Series 854).

7. Dary O, Arroyave G. Sugar fortification with vitamin A: analytical methods for the control and evaluation of sugar fortification of vitamin A. Washington, DC: U.S. Agency for International Development/Opportunities for Micronutrient Interventions; 1996.

8. World Health Organization. Indicators for assessing vitamin A deficiency and their application in monitoring and evaluating intervention programs. Geneva: WHO; 1994.

9. Fleck A. Acute phase response: implications for nutrition and recovery. Nutrition 1988;2: 109-117.

10. Filteau SM, Morris SS, Abbott RA, Tomkins $\mathrm{AM}$, et al. Influence of morbidity on serum retinol of children in a community-based study in northern Ghana. Am J Clin Nutr 1993;58(2):192-197.

11. World Health Organization. Nutritional anemia. Geneva: WHO; 1972. (WHO Technical Report Series No. 3).

12. Honduras, Ministerio de Salud. Encuesta nacional de epidemiología y salud familiar, 1996. Tegucigalpa: Ministerio de Salud; 1997.

13. United Nations Children's Fund. The state of the world's children 1998. New York: UNICEF; 1998.

Manuscript received on 14 March 1998. Revised version accepted for publication on 15 April 1999.
RESUMEN

Desnutrición en niños hondureños de 12 a 71 meses de edad
Para determinar el estado nutricional de los niños de 12 a 71 meses de edad, el Ministerio de Salud de Honduras realizó en 1996 una encuesta nacional sobre micronutrientes en la que se incluyeron mediciones antropométricas. De los 1744 niños que participaron, $38 \%$ presentaban retraso del crecimiento, grave en $14 \% ; 24 \%$ bajo peso, grave en $4 \%$, y $1 \%$ emaciación, grave en $0,1 \%$. El país se puede dividir en tres zonas en función del nivel de retraso del crecimiento y bajo peso: 1) la de baja prevalencia, formada por Tegucigalpa, San Pedro Sula y ciudades medianas; 2) la de prevalencia intermedia, formada por otras zonas urbanas y las zonas rurales del norte y del sur, y 3) la de alta prevalencia, integrada por las zonas rurales del oeste. Mediante un análisis de regresión logística se identificaron los siguientes factores como determinantes importantes del retraso del crecimiento: el nivel de escolaridad de las madres/cuidadoras y de los padres, las fuentes de agua, la localización geográfica de la residencia del niño y la "puntuación de posesiones", referida a la posesión de aparatos como radios, televisores, refrigeradores, equipos de música o planchas eléctricas. A su vez, los factores que predijeron el bajo peso fueron el estado de los micronutrientes, la diarrea, el nivel de escolaridad de las madres/cuidadoras, el tipo de instalación sanitaria y la "puntuación de posesiones". Los datos históricos indican que la prevalencia nacional de desnutrición crónica ha cambiado poco en los últimos 10 años, pese a la importante mejoría de los servicios de salud y a la puesta en marcha de varios planes nacionales de alimentación y nutrición. Es posible que estas intervenciones positivas hayan sido contrarrestadas por los lentos progresos del desarrollo económico. Las futuras intervenciones nutricionales deberían tomar en consideración las necesidades y prioridades percibidas a nivel doméstico, con el fin de fijar objetivos nutricionales realistas. 